


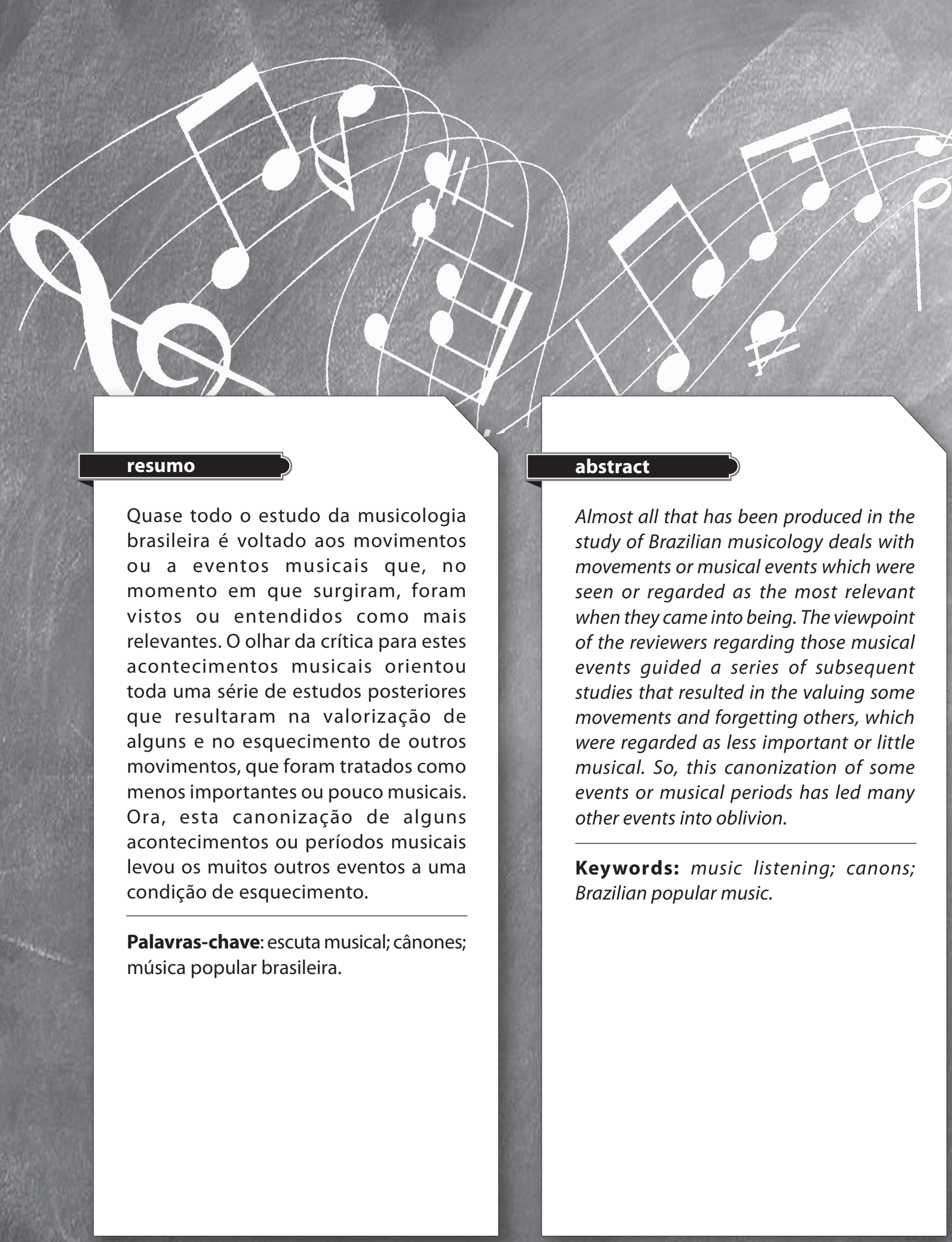


da nossa música popular¹. A construção objetiva de um saber erudito só se inicia com o advento da República, através dos ideários positivistas e com o processo de industrialização no Brasil, calcado em um racionalismo industrial voltado à produção, que valorizou a sobreposição de um saber erudito sobre o saber popular.

“[...] o último quartel do século passado [XIX] marca o início da revolução que se iria operar, pois as campanhas abolicionistas e a urbanização paulatina das condições de existência iriam deitar por terra as relações patrimonialistas e a concepção tradicional do mundo correspondente [...]. Então começa a desagregação da cultura popular. O 'escravo' e o 'homem do povo' desconheciam quase completamente os motivos e os padrões ideais que tornavam atitudes, técnicas e instituições tradicionais valores socialmente pouco conspícuos e desejáveis nas camadas dominantes" (Fernandes, 1979, p. 31).

A imprensa só chegou ao Brasil em 1808, com a família real portuguesa, e somente a partir de 1821 começou a ter uma relativa liberdade, posto ser a tipografia régia a principal e uma das únicas existentes no Brasil até essa data, funcionando assim como um crivo de censura às publicações. Só a partir daí a imprensa no Brasil começou a alçar voos próprios.

Nossa própria elite olhava para a Europa copiando-a, quando nossa cultura popular estava sendo gestada, isso nos séculos XVIII e XIX. E quando voltou seu olhar à cultura de seu país não a reconheceu como sua. Se antes nossa elite almejava ser europeia, hoje sonha ser de Miami, de Nova York.

Por fim, a mídia. Isso sem falar no poder que esta tem hoje, sobretudo no controle sobre os rumos políticos do país, mas me refiro aqui à

1 O saber oral, por não ser registrado, favorece uma miríade de percepções de um mesmo acontecimento pertinentes a cada pessoa, a cada grupo, a cada cultura, a cada olhar. "El relato oral es móvil, lo que impide su esclerosamiento. A diferencia dellibronocaduca:se transforma. Es un médio de transmisión de conocimientos queen mayoro menorgrado vehicula una carga subjetiva, la que incluye los fermentos que permitieron al mito cambiar de máscara, responder a las nuevas situaciones" (Colombres, 1995, p. 139). crítica musical, que sempre associou suas análises sobre o novo que surgia tendo como referência o que já existia e havia servido de base para as modificações que ora aconteciam. Essas críticas acabaram por nortear as primeiras produções de textos acadêmicos sobre música, as quais traziam um primeiro material pensado e escrito sobre seus objetos de pesquisa.

Cânones podem ser criados a partir de uma aceitação espontânea gerada pela própria funcionalidade que guardam em si.Podemos reputar também essa formação de cânones à Igreja do Vaticano, que, incomodada com as novas formas que o catolicismo ganhava na América Latina, visando a restaurar um catolicismo canônico, baixou determinações de conduta a partir de diversos concílios desde 1830, chamados, no Brasil, de romanizações².

Se, por um lado, a falta do acesso ao saber erudito limitou o crescimento da população na direção de um saber predefinido, por outro, deu liberdade a cada povo, a cada grupo de cada etnia de construir seus próprios caminhos a partir dos referenciais culturais que estavam às suas mãos, o saber oral, o saber popular.

Essa grande diversidade cultural que temos no Brasil suporta, em parte expressiva, a diversidade da música popular brasileira, que foi e ainda é uma tradição calcada na oralidade. Ainda "tiramos música de ouvido", ensinamos muitas vezes sem o papel, a partir de uma imitação que se torna criativa desde o momento da transmissão até a assimilação dessa nova informação.

A interação étnica e cultural certamente favoreceu o aumento da diversidade. Uma manifestação musical, quando migrada para outro local distinto, com o tempo tendia a se transformar em outra modalidade. A própria falta de normatização e sistematização do conhecimento fez essas modalidades se portarem de maneiras semoventes, sofrendo modificações

2 Portugal era um Estado católico e, como tal, tinha a obrigação de manter as igrejas no Brasil. Não tendo dinheiro para tal façanha, deixou esse encargo nas mãos das poucas irmandades aqui existentes e de inúmeras comunidades leigas que, por sua vez, foram misturando ritos e superstições nesse catolicismo puro. Daí a intenção do Vaticano em restaurar um catolicismo canônico (Abreu, 1999). 
conforme o tempo passava ou novas situações se apresentavam.

É importante que não nos esqueçamos que a África se conheceu na América, segundo nos lembra o músico Benjamim Taubkin. A América foi o grande palco de encontros das muitas e muitas etnias provenientes do continente africano.

\section{EDUCAÇÃO CANÔNICA}

A partir do momento em que recebemos uma educação calcada nos cânones e não na diversidade que o mundo oferece, nossa percepção torna-se unívoca e deixamos, assim, de perceber o mundo de maneira multidimensional. Essa univocidade se dá sobretudo a partir do que o sistema de ensino nos mostra e do que a mídia nos oferece.

Numa educação canônica, nossa percepção se restringe ao que entendemos como o mundo que elegemos, e tendemos sempre a desqualificar ou a não reconhecer o que desconhecemos, colocando toda essa gama de informações numa vala de elementos genéricos.

Como exemplo, podemos pensar na nossa horta ou no nosso canteiro de ervas. Lá tudo tem nome e função, exceto o que desconhecemos. Assim, "este é o alface, aquela, a beterraba; esta, a hortelã, ali, a erva-de-são-joão, boa para a cólica dos nenês; artemísia, boa para a nevralgia, poejo, que é tônico, alfavaca-anis, para cólicas de todos os tipos... aquela?... aquela eu não sei, aquela é mato".

No mato pode estar escondida a maior panaceia da horta, no entanto, como não nos foi ensinada nem mostrada a possibilidade de aquela planta ser algo formidável, toda vez que a olhamos, não a vemos.

Os cânones tímbricos são tão fortes que meus alunos de Percepção Musical agradecem por poder ouvir os discos para transcreverem as músicas, sem instrumentos, pois de início são acostumados a relacionar as alturas a serem percebidas e escritas a partir do timbre do piano, que é o principal instrumento usado nas aulas de Percepção Musical. Nessas aulas, uma aluna não conseguia reconhecer o canto afinado do Cego Oliveira, um cantador de rua, dada a sua emissão vocal ser muito diferente de tudo o que ela havia escutado a vida toda, em sua formação estritamente clássica e canônica. Ela insistia em que ele não cantava, que falava o poema com prosódia marcada.

Para completar essa estrutura que faz perdurar os cânones, hoje em dia, mais do que nunca, a arte está atrelada a um sistema de divulgação, digo, de promoção na mídia. Rádios, revistas, jornais e TVs funcionam como outdoors.

\section{O RIO DE JANEIRO}

Desde o início do século XIX até a metade do século XX, foi o Rio de Janeiro, então capital federal, o principal palco dos encontros étnico-culturais e dos acontecimentos artísticos ocorridos no Brasil. Ainda mais por ter no samba uma música de alta permeabilidade, que soube dialogar com todas as musicalidades caribenhas que aqui chegaram pela via do cinema e do governo estadunidense, como ocorreu no período da política de boa vizinhança.

No Rio se situavam as duas principais rádios do país, a Nacional e a Mayrink Veiga.

Nesse momento observamos que os cânones foram se estruturando de maneira não intencional, embora, a partir de 1940, reparemos numa permanência de procedimentos formais e tímbricos, seja na estrutura formal, seja no som orquestral ou na impostação vocal.

Podemos citar a presença da canção estadunidense vinda pela via do cinema como uma força que muito influenciou e transformou a música popular brasileira desde os anos 1930. Não foi à toa que Ismael Silva e Noel Rosa escreveram o samba "Não Tem Tradução".

"O cinema falado é o grande culpado da transformação/ desta gente que pensa que um barracão prende mais que um xadrez [...] as gírias que o nosso morro criou/ bem cedo a cidade aplaudiu e usou/mais tarde o malandro deixou de sambar dando pinote/ só querendo dançar o foxtrote/ essa gente hoje em dia que tem a mania de exibição/ não entende que o samba não tem tradução no idioma francês/ tudo aquilo que o malandro pronuncia com voz macia é brasileiro/ já passou do português/ amor lá no morro é amor pra chuchu/ as gírias no morro não são $i$ love you/ e este papo de alô, alô boy, 
alô Johnny/ só pode ser conversa de telefone" (Rosa \& Silva, 1933).

A influência foi forte o suficiente para fazer o samba-canção ganhar a estrutura formal da canção de jazz e da canção de musicais dos EUA, com uma parte $\mathrm{A}$, outra $\mathrm{B}$, a volta instrumental de $\mathrm{A}$ ou B e a finalização com voz na parte A ou B.

Ora, tínhamos aqui canções na forma rondó ternária, como o choro, monoformal, como algumas cançonetas, rondós binários, como "Pescador", do Xisto Bahi ${ }^{3}$, e inúmeros sambas do Sinhô. E essas conviviam sempre. Incorporar a estrutura formal de outras músicas requer uma forte aceitação destas como influência. Forma é alicerce.

A partir dessa incorporação formal pelo samba-canção, grande parte da produção musical brasileira da época seguiu esse padrão, só sendo quebrado pelo advento da Bossa Nova na gravação de "Chega de Saudade", de Tom Jobim e Vinícius de Moraes ${ }^{4}$. A Bossa Nova romperá alguns cânones, criando outros, não por vontade própria, mas por fina qualidade e criatividade musical que acabaram certificando uma MPB de excelência.

Em 1960, notamos uma estruturação de padrões em procedimentos composicionais e tímbricos que acabaram fortalecendo a estruturação de cânones na MPB. Podemos pensar na obrigatoriedade de toda música boa possuir uma harmonia sofisticada, como se só a harmonia pudesse atestar a sofisticação de uma música. O que dizer do contraponto, das texturas, da prosódia, dos ritmos? As timbragens dos primeiros discos de Milton, Chico e Edu Lobo ainda guardam um padrão sonoro comum à Bossa Nova e ao cool jazz, padrão este que será rompido pelos tropicalistas 5 .

$\mathrm{Na}$ realidade, todas as conquistas musicais registradas na música popular brasileira chegavam

3 Primeira música brasileira gravada em disco, no ano de 1902, pela Casa Edson, Rio de Janeiro.

4 Esta, sem interlúdio instrumental, com orquestração enxuta funcionando mais como uma moldura sonora, volta do violão e de um canto sem impostação ao centro da cena sonora e utilização das tensões harmônicas, sobretudo na voz, característica herdada do choro, ainda do século XIX.

5 Ouvir"Travessia", de Milton Nascimento, "Carolina", deChico Buarque, "Resolução", de Edu Lobo. Esta última, mais presa à sonoridade dos jazz trios. pela via do Rio de Janeiro e da música ali produzida. Assim, definiu-se o que foi chamado de linha evolutiva da MPB, um campo consolidado de conquistas que vinha pela via do choro, do samba, do samba-canção e da Bossa Nova. A Tropicália, conscientemente, implodiu esse conceito a partir da paródia, da carnavalização e do deboche e também por olhar para o Brasil de dentro e trazer dali sonoridades e procedimentos que já eram utilizados pela chamada canção de protesto.

Notemos que, dentre os compositores de samba nos anos 1930, temos alguns mineiros, como Geraldo Pereira, Ataulfo Alves e Ary Barroso. Possivelmente tiveram estes, na sua formação cultural, algo mais que apenas o samba, posto serem mineiros. Aí já percebemos a força de uma música que se tornou, durante um período, referencial a todos que ansiavam viver dela.

O próprio Luiz Gonzaga precisou se travestir de cangaceiro, ganhando assim um ar de exotismo, para conseguir se inserir com o baião e outras particularidades nordestinas no seio da música popular brasileira central, a produzida, divulgada e, em parte, consumida no Rio de Janeiro. Se escutarmos a música "Baião", gravada pelos Quatro Ases e Um Coringa, em 1946, ouviremos as vocalizações "roliudianas" presentes nessa interpretação. O mesmo ocorreu com Jackson do Pandeiro, em 1954.

Ora, o que não era, então, essa MPB era música regional, sendo o termo "regional" usado mais como um qualificativo do que como um designativo. Não tratamos Grande Sertão: Veredas, nem Canções Praieiras, de Dorival Caymmi, como obras regionais, embora o sejam. Mas estas são tão grandiosas que superam a designação "regional", sendo tratadas como nacionais ou universais (Chiappini, 1995). A música de outras regiões, não atingindo um padrão de excelência ou não dialogando tímbrica nem ritmicamente com a corrente central da MPB, passa a ser tratada como regional ${ }^{6}$.

Veremos que uma maior ruptura se dará com a canção de protesto, a qual, além das sempre citadas letras de música de alta relevância político-ideológica, trouxe para o seio da MPB, pela via

6 O Prêmio da Música Brasileira ainda insiste em manter uma categoria regional, o que fez a cantora Elba Ramalho se indignar ao recebê-lo, alegando que se achava uma cantora de música brasileira. 
dos festivais, novos elementos rompendo vários cânones sonoros, com novos timbres (viola de dez cordas, queixada de burro, caxixi), novos ritmos que não o samba, o baião, a toada, o bolero e o samba-canção ${ }^{7}$, e também novos modos (escalas), usuais até então apenas na música do Nordeste. A utilização desses modos abria novas janelas para o uso das harmonias.

A contribuição da canção de protesto foi fundamental para que possamos entender a dissolução de um cânone sonoro que se mantinha no Brasil pela via de uma música "central" produzida no Rio de Janeiro.

A continuidade desse ideário temático da canção de protesto se manteve nas vozes de diversos cantadores por todo o Brasil, dos quais Dércio Marques foi o grande expoente. Músico inquieto e generoso, Dércio, por décadas, juntou pontas soltas desse canto no Brasil, ligando músicos de leste a oeste e de norte a sul do país. Vale pensarmos hoje em canção de protesto não como uma música que se levanta contra um regime ditatorial ou um Estado de exceção, mas sobretudo como uma música que narra o cotidiano de povos, grupos, etnias e pessoas que só encontram nela uma maneira de registrarem a sua história.

Dércio foi o grande articulador de um forte movimento de música ocorrido em Minas Gerias, no início dos anos 1980, que lançou artistas como Titane, Paulinho Pedrazul, Rubinho do Vale, o poeta Gildes Bezerra e a dupla Ivan e Pricila. A diversidade que aflorava no Brasil nos anos 1980 foi totalmente ofuscada por uma ação midiática ligada às gravadoras, que elegeram o chamado BRock como a música do momento, à custa de muito jabá ${ }^{8}$.

\section{MUDANÇA DE PARADIGMAS}

Agora chegamos a um ponto crucial. A Bossa Nova acabou por reaquecer o mercado da música instrumental brasileira que, desde os

7 Ouvir os discos Quarteto Novo, de 1967, e Canto Geral, de Geraldo Vandré, de 1968.

8 "Jabá" vem do tupi "jabaculê", que significa "oferenda". No caso, uma oferenda (propina) que as grandes gravadoras (majors) davam à mídia para esta veicular os seus produtos artísticos. anos 1930, com o emergir do samba e o ocaso do choro como música de mercado, vivia em baixa divulgação.

Com os jazz trios, notamos um renascimento dessa música instrumental, mas será a partir do Quarteto Novo que surgirá uma nova perspectiva de uma música instrumental construída a partir de elementos que até então não haviam sido utilizados como material temático pelos instrumentistas, os da música nordestina.

Mais que só um grupo de música instrumental brasileira, o Quarteto Novo foi precursor de uma nova maneira de se fazer música instrumental no Brasil, utilizando elementos de culturas tradicionais, no caso, as nordestinas, mesclados a um contraponto rebuscado, mudança de texturas, de andamentos, de densidade instrumental, alternância de compassos de dois tempos (2/4) para compassos de sete tempos (7/8), harmonização complexa mesclando o tonal com o modal, inserção da viola brasileira junto a uma percussão construída por caxixi e queixada de burro junto à bateria. Isso ocorreu num momento em que a referência da música instrumental brasileira estava pautada pelos jazz trios.

Se pensarmos a canção não como uma melodia acompanhada ou como texto, melodia e harmonia, mas como uma estrutura musical que resiste à expansão ${ }^{9}$, a música do Quarteto Novo tem vários movimentos num curto espaço de exposição sonora.

A linguagem musical apresentada por esse grupo apontou para uma música de caráter universal construída a partir de elementos das culturas nordestinas aos quais estavam inseridas todas as aquisições obtidas pela MPB ao longo de sua história, como sofisticação harmônica e apuramento melódico.

O Quarteto Novo gravou em 1967 e o Quinteto Armorial, em 1974. Ambos lançaram estéticas sonoras novas e, no entanto, são preteridos em grande parte dos estudos, que vão focar quase sempre os mesmos assuntos.

9 O que caracteriza a música clássica, sobretudo a partir de Beethoven, é a utilização de um material temático desenvolvido sistematicamente. Observar o primeiro movimento da Quinta Sinfonia, de Beethoven. Já a canção, esta resiste à expansão, não quer se expandir. Expõe-se e termina. 
A proposta estética do Quinteto Armorial, no aspecto tímbrico, foi além da do Quarteto Novo quando passou a utilizar instrumentos típicos da cultura nordestina, como o marimbau e a viola de repente (notemos aqui a diferença entre a maneira de tocar de Heraldo do Monte, do Quarteto Novo, e a de Antônio Madureira, do Quinteto Armorial).

A crítica jornalística foi, a meu ver, determinante na criação desses cânones. Como já citei, quando surgia algo novo, a crítica, na busca de uma compreensão, sempre associava o novo aos eventos ocorridos anteriormente. Assim, ficou fácil entender a Bossa Nova, olhando para o samba-canção; entender a Tropicália, olhando para a Jovem Guarda e para a canção de protesto. Mas não foi tão fácil entender o Clube da Esquina, posto ele trabalhar com sínteses que nem sempre eram perceptíveis a uma audição rápida. Síntese de todas as aquisições efetuadas pela MPB ao longo de sua história.

Dessa maneira, toda uma ordem de estudos acadêmicos posteriores, que tiveram como primeiras fontes de apoio as críticas jornalísticas, apontou seu fogo aos movimentos que foram, por essa crítica, canonizados, como aconteceu com a Bossa Nova, a Jovem Guarda e a Tropicália. Basta escrevermos num buscador da internet "bossa nova pdf”, "tropicália pdf”, “jovem guarda pdf" para percebermos o volume de artigos que aparecem. Depois, escrever "clube da esquina pdf", "quarteto novo pdf", "movimento armorial pdf" ou mesmo "música caipira pdf", para constatarmos o grande degrau de interesses ou desinteresses que se nos apresenta.

A canonização de alguns eventos foi positiva no que toca aos vários e aprofundados estudos que foram desenvolvidos, mas também negativa, por afastar do foco e das prioridades outros eventos musicais de igual ou maior importância que esses muito estudados.

Podemos agora olhar para a música caipira, que sequer foi aceita como um braço da MPB. Talvez por conta da depreciação socio-histórica a que foi submetido o caipira migrante na cidade grande durante o êxodo rural. Reforçada por uma visão etnocêntrica, já citada, sua música passou a ser tratada como menor, e não havia rendido, até pouco tempo atrás, um único estudo sobre suas particularidades musicais onde fossem ressaltadas importâncias até então não observadas, tal qual o mato na horta. Sua diversidade rítmica e tímbrica sem igual são características até há pouco não reconhecidas por todos como sonoridades presentes no que chamamos de músicas étnicas. As atribuições sonoras dadas a ela, como som raspado, rústico e grosseiro, são na realidade sonoridades que as músicas clássica e popular se mostram incapazes de produzir. A utilização de inesperadas prosódias (o ritmo da fala), pela falta aparente de conhecimento da métrica, também resulta em inesperadas articulações rítmicas da fala. Essa música operou na manutenção dos valores dos migrantes em São Paulo a partir de sua radiodifusão. Contando histórias e transmitindo valores, a música caipira manteve esses migrantes enraizados. Reenraizados. Mesmo assim, ela sequer foi entendida como um braço da MPB.

Dessa forma, tendo a crer que a principal referência da musicologia, mais que os livros, sejam os discos, pois se, de alguma maneira, os livros podem perpetuar visões secundárias ou terciárias, mas nunca primárias, sobre os temas estudados, com os discos acessamos a matéria em sua essência. Que privilégio o de podermos trabalhar com as fontes primárias.

A escuta como primeira e não única referência pode ser reveladora de aspectos antes ocultos ou não enunciados. O que dizermos da obra de Elomar? Se Elomar for tratado como música regional, Caymmi, em parte de sua obra, deverá ter o mesmo destino, pois o que este canta sobre o mar de fora, aquele canta sobre o mar de dentro, o sertão. Se as harmonizações de Caymmi sofisticam a MPB a partir da utilização de procedimentos oriundos de harmonias debussyanas, as de Elomar sofisticam a MPB a partir de elementos do Renascimento, no que toca à utilização de polimodalismos fundidos aos ritmos da caatinga.

Talvez um dos eventos musicais que mais nos saltem aos olhos como esquecidos dentro do contexto da história canônica da MPB seja o do Clube da Esquina. Partir de categorizações predefinidas, como a de formação cultu- 
ral, de Raymond Williams ${ }^{10}$, sobre grupos ou movimentos, exclui a linguagem musical do processo de entendimento do fenômeno sonoro. Não perceber e não considerar a unidade sonora presente durante mais de 13 anos nas produções dos inúmeros músicos do chamado Clube da Esquina como um fator de unidade que os agregaria em um movimento musical é o mesmo que não perceber essas mesmas características na Bossa Nova. Essa definição que acaba por regionalizar o caráter musical do Clube da Esquina poderia ser trazida também à Bossa Nova, que foi mais que regional, foi local, na zona sul da cidade do Rio de Janeiro. Ou será que o Rio, por ser nessa época a capital federal, faz alguns pressuporem que a sua linguagem seja nacional? Em que outro lugar do Brasil fala-se o português como no Rio de Janeiro? Não seria a fala deles regional? Paira aí uma aceitação impensada sobre valores e costumes que acabam por definir um local como o centro emanador de todas as estéticas musicais presentes e colocando-o em uma posição inquestionável. Não seria mais uma atitude etnocêntrica repetida, impensada ou assumidamente, por muitos?

Trazer concepções predefinidas de outros segmentos do conhecimento humano e tentar enquadrar nelas os fenômenos e acontecimentos musicais me parece temerário por não dar mérito à música dentro do estudo musicológico. Como exemplo, o antropólogo Sidney Valada- res Pimentel questiona as categorizações feitas por José de Souza Martins sobre a música caipira e sertaneja. Para Martins, a partir do momento em que passou a ser gravada, essa música perdeu a sua função ritual, tornando-se um produto mercadológico, devendo ser chamada agora de música sertaneja. Uma visão funcionalista. Ora, tal definição não muda a música feita, mas apenas aponta uma nova destinação para essa produção musical. Para Pimentel, a música caipira ou sertaneja - que podem ser entendidas como sinônimos -, gravada ou não, é a mesma para quem a produz, para quem a consome e para quem a veicula, pois o imaginário que as suporta é o mesmo. Dessa forma, inserir acontecimentos musicais de grande estatura em "caixinhas de entendimento e categorização" reforça uma postura recorrente de não relevar a música dentro dos méritos das questões musicológicas.

Cabe aqui uma pequena observação sobre o cânone. Até que ponto acessamos pela mídia algo que não seja tratado como um cânone? O mesmo pode ocorrer com parte da literatura sobre o assunto? Corremos o perigo de achar que os acontecimentos canônicos foram os únicos existentes, esquecendo que o que fez e faz a música popular brasileira ser ainda uma das grandes músicas populares do mundo não é apenas a qualidade de sua produção, mas principalmente a diversidade musical que ela comporta em si.
10 Vários autores ligados ao segmento da sociologia e da história insistem em enquadrar o Clube da Esquina numa categoria que Williams define como formação cultural e não como um movimento musical. Isso se dá por não relevarem o material musical produzido por aqueles e talvez por desconhecimento ou inabilidade em analisá-lo. 


\section{BIBLIOGRAFIA}

ABREU, Martha. O Império do Divino. Rio de Janeiro, Nova Fronteira, 1999.

BORDIEU, Pierre. O Poder Simbólico. Rio de Janeiro, Bertrand Brasil, 1989.

CAMPOS, Augusto de. Balanço da Bossa e Outras Bossas. $3^{\text {a }}$ ed. São Paulo, Perspectiva, 1978.

CHIAPPINI, Lígia Moraes Leite. "Velha Praga? Regionalismo Literário Brasileiro", in Ana

Pizarro (org.). América Latina - Palavra, Literatura e Cultura. Campinas, Editora da

Unicamp, 1995.

COLOMBRES, Adolfo. "Palabra y Artifício: Las Literaturas 'Bárbaras'”, in Ana Pizarro (org.).

América Latina - Palavra, Literatura e Cultura. Campinas, Editora da Unicamp, 1995.

ELIAS, Norbert. O Processo Civilizador. Rio de Janeiro, Zahar, 1993, vol. 1.

. O Processo Civilizador. Rio de Janeiro, Zahar, 1994, vol. 2.

FERNANDES, Florestan. Folclore e Mudança Social na Cidade de São Paulo. Petrópolis, Vozes, 1979.

GARCIA, Tânia da Costa. "Redefinindo a Nação. Canção Popular e Folclore: Um Estudo Comparativo entre Chile, Argentina e Brasil no Pós-Segunda Guerra Mundial",

in Tânia da Costa Garcia; Lia Tomás (orgs.). Música e Política. São Paulo, Alameda, 2013.

GINZBURG, Carlo. O Queijo e os Vermes. São Paulo, Companhia das Letras, 2013.

JAMBEIRO, Othon. Tempos de Vargas: O Rádio e o Controle da Informação. Salvador,

Editora da UFBA, 2004.

MARTINS, José de Souza. Capitalismo e Tradicionalismo. São Paulo, Pioneira, 1975.

PIMENTEL, Sidney Valadares. O Chão É o Limite. Goiânia, Editora da UFG, 1997.

SAHLINS, Marshall. "Cosmologias do Capitalismo", in Anais da XVI Reunião da Associação Brasileira de Antropologia. Campinas, ABA, 1988.

SANT'ANNA, Afonso Romano de. Música Popular e Moderna Poesia Brasileira. Petrópolis, Vozes, 1978.

TATIT, Luiz. O Cancionista. São Paulo, Edusp, 1995.

TINHORÃO, José Ramos. História Social da Música Popular Brasileira. Lisboa, Editorial Caminho, 1990.

VILELA, Ivan. Cantando a Própria História - Música Caipira e Enraizamento. São Paulo, Edusp, 2013.

\section{Discografia}

Escuta apurada de inúmeros discos da MPB. 